\title{
Armonías de papel: la tradición clásica de la música de las esferas en el Renacimiento*
}

\author{
Ana Elena GoNZÁLEZ TREVIÑo \\ Universidad Nacional Autónoma de México
}

\begin{abstract}
Above this vaste and admirable Frame, This Temple visible, which World we name... There is a World, a World of perfect Blisse, Pure, immateriall, bright, more farre from this, Than that high Circle which the rest enspheares...

W. Drummond, Song ii
\end{abstract}

Hacia 1670, el teólogo, filósofo y poeta inglés Thomas Traherne escribía en un tratado teológico de astronomía que las esferas celestes son el mecanismo que hace girar armoniosamente al universo. Pero en su manuscrito se observa que la palabra son está tachada, y que añade la siguiente aclaración: "Las observaciones de Tycho Brahe han demostrado que esto es lo que se creía en el pasado, pero es enteramente probable que las esferas celestes como tales ni siquiera existan" (Traherne, fol. 134r.). Cabe aclarar que las observaciones de este astrónomo danés se conocían desde un siglo antes. Las leyes de Kepler, su discípulo, se publicaron cincuenta y sesenta años antes del momento en que escribe Traherne. La nueva astronomía es de 1609, y Las armonías del mundo de 1619. Traherne, sin ser propiamente un científico, era teólogo universitario oxoniense, formado en una época en la que teología y ciencia aún formaban parte de un todo orgánico. Por esta razón tanto él como otros teólogos contemporáneos mezclaban con naturalidad estas áreas del saber: Traherne era fiel admirador de Robert Boyle y Isaac Barrow, el maestro de matemáticas de Newton; y tanto Boyle como Newton escribieron prolíficamente sobre teología. Barrow, a su vez, abandonó las matemáticas para dedicarse a cosas "verdaderamente serias" como

* Una versión resumida de este trabajo se presentó en la Escuela Nacional de Música el 7 de febrero de 2002 en el Primer Encuentro Interdisciplinario de Música y Poesía del Renacimiento y Barroco. 
la teología. Traherne escribe principalmente sobre teología, pero en sus obras abundan referencias y especulaciones que en el presente se considerarían científicas; además se preciaba de estar muy actualizado. (La difusión científica en el siglo XVII iba a otro ritmo, claro está.) Sin embargo, aun cuando reconoce que hay serias dudas acerca de la existencia material de las esferas, se observa en toda su obra una gran reticencia a abandonar el lenguaje ptolemaico.

Y no es un caso aislado. Durante todo el siglo XVII, e incluso el XVIII, muchos poetas, teólogos y filósofos seguían aludiendo a las esferas celestes y a su música, sin importar que existieran o no. ¿A qué se debe esto? La razón es muy sencilla: la tranquilidad mental de creer que el hombre vivía en un universo ordenado, la sensación de control que transmitía la regularidad geométrica del sistema ptolemaico, su belleza hipnótica y fascinante (sin menospreciar el hecho de que estuvo vigente durante quince siglos por lo menos), resultaron muy prácticas para representar no sólo la supuesta forma del universo, sino que fungieron también como una retórica utilísima para describir toda clase de hechos naturales, morales, religiosos y artísticos. Y es precisamente como retórica que cobró vida propia y se propagó dentro de muchos tipos de discurso. De hecho, se infiltró a tal grado en la psique occidental, que el uso la enriqueció y la convirtió en un rico arsenal ideológico y poético de lugares comunes que, junto con la mitología y los temas bíblicos, fuera una de las grandes fuentes de imaginería del Renacimiento.

Los orígenes de la cosmovisión ptolemaica se encuentran en diversos textos de filosofía clásica entre los que destacan tres: el décimo y último libro de la República de Platón, el tratado Sobre el cielo de Aristóteles, y el llamado "Sueño de Escipión" que cierra el libro de la República de Cicerón. Este último relata cómo Escipión el Africano, conquistador de Cartago, tuvo un sueño en el que le fue concedida una visión del universo experimentada en un vertiginoso vuelo ascendente. Cruza una a una todas las esferas celestes y observa los mecanismos que las hacen girar. En un momento dado, le pregunta a su guía:

¿Qué sonido es ése... que tan poderoso y suave llega hasta mí? -Esa armonía -me contestó-, formada por intervalos desiguales, pero proporcionados con extraordinaria perfección, resulta del impulso y movimiento de las esferas, que confundiendo los sonidos graves y agudos en acorde común, hace de esos tonos variados melodioso concierto; esos grandes movimientos no pueden realizarse en silencio, y la naturaleza ha querido que en un extremo de la escala armónica resuenen los sonidos graves y en el otro los agudos. Así pues, las esferas más altas, las del firmamento estrellado, cuya carrera es 
más rápida, lanzan agudo y penetrante sonido; mientras del globo inferior de la luna solamente brota nota grave y opaca. En cuanto a la tierra, permanece inmóvil en medio del mundo, invariablemente fija en este profundo abismo (Cicerón 1981: 76).

Cabe destacar aquí que el texto latino dice acuta cum gravibus temperans, varios aequalibiter concentus efficit (Cicerón 1866: 276). Para puntualizar la traducción de Navarro y Calvo, pues el término confundir se presta a ambigüedades, obsérvese que lo agudo no es confundido, sino temperado o templado con lo grave, es decir, extremos discordantes conjugados en un melodioso equilibrio. El concepto de templanza posee una conveniente ambivalencia al designar tanto el fenómeno "físico" de la resonancia bien templada o "acordada" de las esferas, como una virtud en el campo de la ética; una virtud, por cierto, de las más exaltadas en el Renacimiento (Isacoff 2001: passim). La idea de que los extremos discordantes puedan llegar a producir algo bueno de su diferencia se expresa en el tópico renacentista de discordia concors y en la definición misma de la armonía como combinación acorde. Esto tiene profundas implicaciones teológicas y también políticas con respecto a la diversidad en la creación y en particular la de los seres humanos, pues proporciona un modelo de convivencia ideal que justifica las diferencias de estado y condición. Más aún, tenemos también la idea de que el espacio sublunar es donde se produce el sonido más grave y opaco; el hombre caído vive en el centro mismo de la corrupción, y esto dificulta enormemente la convivencia armoniosa (Tillyard 1984: 93).

El sueño de Escipión en sí fue muy popular en el Renacimiento. Es en buena medida, por ejemplo, la fuente inspiradora del vuelo imaginario que hacen Don Quijote y Sancho con los ojos vendados, montados en un caballo de madera por las distintas "regiones del aire" (Cervantes 1969: 484-493). Muchos otros autores, incluyendo a Traherne antes citado, se sintieron atraídos también por la fantasía del vuelo astral.

La versión aristotélica es la que influyó de manera más directa en Ptolomeo, y es la más científica de las tres. Según ciertos principios físicos y geométricos esbozados en Sobre el cielo, Aristóteles propone que debe haber cincuenta y cinco esferas que giran cada una sobre su propio eje. Sus ideas se complementan con las de Eudoxio de Cnido, condiscípulo suyo en la Academia platónica, que fue realmente el primero en proponer un modelo geométrico para describir los movimientos de los astros con respecto al Zodiaco, sólo que en el sistema de Eudoxio nada más hay veintisiete esferas.

Aristóteles clasificaba las sustancias según sus movimientos naturales. Todo lo ubicado en la esfera sublunar, es decir, la Tierra y su atmósfera, 
consistía de una mezcla de tierra, agua, viento y fuego. Estos elementos, en este orden, iban del más pesado al más ligero, por lo que su movimiento natural era de caída hacia el centro de la Tierra o hacia arriba, hacia el cielo. Como los movimientos celestes eran circulares y no en línea recta, el cielo mismo debía estar compuesto de un quinto elemento, el éter, que debía ser eterno, perfecto e inmutable. La teoría de los cuatro elementos y la quintaesencia estaba ciertamente vigente todavía durante el Renacimiento y gozó de enorme popularidad entre los poetas.

Quizá Eudoxio no pensara en las esferas más que como una representación de los movimientos planetarios, sin que necesariamente hubiera unas esferas materiales girando alrededor de la Tierra, pero Aristóteles sí concebía las esferas como un sistema material verdadero. Por eso se ocupa de resolver los problemas mecánicos de cómo pueden anidarse tantas esferas concéntricas, todas girando a distintas velocidades. Así, deduce que entre una esfera planetaria y otra debe haber otras cuatro esferas que articulan sus movimientos. Detrás de estos razonamientos subyace el problema de las causas primeras del movimiento. Aristóteles propone que existen sustancias y principios inamovibles que se traducen posteriormente al concepto de primum mobile, el primer motor, ubicado en la última esfera, más allá incluso de la esfera de las estrellas fijas, el cielo de los cielos, que proporciona el ímpetu para todos los movimientos celestes. Estas ideas se representan de manera gráfica en la figura 1 de la Cosmographia de Pedro Apiano de 1539. Obsérvese que en el exterior del Decimum Coelum se ubica el Empíreo, señalando el lugar donde habita Dios mismo.

La asimilación de esta faceta del aristotelismo a la cristiandad renacentista adoptó formas insospechadas. En un curioso poema pastoril de Thomas Randolph, de 1638, titulado "Poetry and Philosophy", el poeta y músico es en realidad un filósofo cuyo arte le descubre los secretos del universo. Éste es un lugar común asociado típicamente con la búsqueda alquímica, pero aquí se conjuga con una rara imagen de Aristóteles, exaltado como pastor cantante, hipotéticamente ayudando a los ángeles a hacer girar las esferas (Grierson y Bullough 1951: 424). Este tipo de imagen, rayana en la ramplonería, se da cuando las nociones abstractas se llevan a un extremo material, especialmente todo lo relacionado con los ángeles; se asocia de manera directa con la estética barroca. Vale la pena citar el pasaje relevante. Habla el pastor filósofo, Damon:

When I contented liv'd by Cam's fair streams,

Without desire to see the prouder Thames,

I had no flock to care for, but could sit 
Under a willow covert, and repeat

Those deep and learned layes, on every part

Grounded on judgment, subtilty, and Art,

That the great Tutor to the greatest King,

The shepherd of Stagira, us'd to sing:

The shepherd of Stagira, that unfolds

All natures closet, shows what e'er it holds;

The matter, form, sense, motion, place, and measure

Of every thing contain'd in her vast treasure.

How Elements doe change; What is the cause

Of Generation; what the Rule, and Laws

The Orbs doe move by; Censures every starre,

Why this is fixt, and that irregular;

Knows all the Heavens, as if he had been there,

And help't each Angell turn about her spheare.

("Poetry and Philosophy", vv. 57-74)

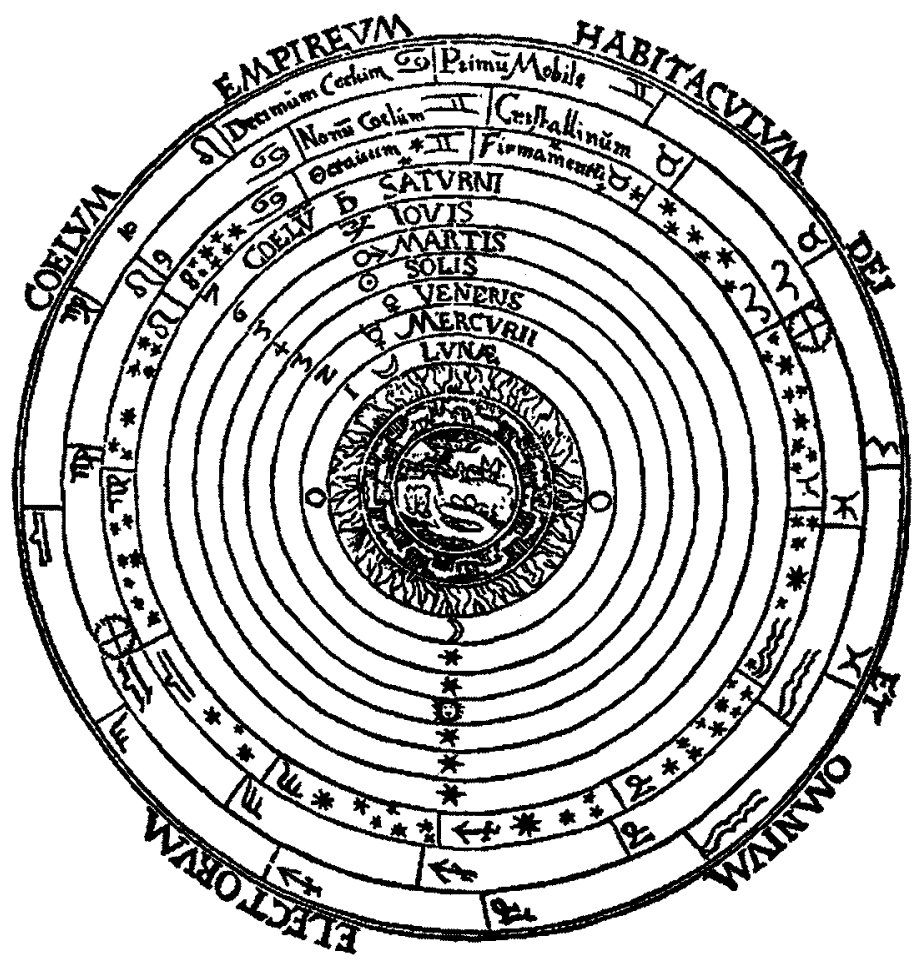

Fig. 1: Pedro Apiano, Cosmographia (1539). 
Sin lugar a dudas, la fuente más influyente en lo que respecta a estas ideas en los siglos XVI y XVII es la que antecede a Cicerón y Aristóteles. La República de Platón termina con un discurso de Sócrates en el que cuenta la historia de la visión de Er. A diferencia de la vertiginosidad física del sueño de Escipión, la experiencia de Er es una visión más estática y de tipo religioso acerca de lo que acontece después de la muerte: el descenso de los malvados al infierno y el ascenso de los buenos al cielo, pasaje que fue muy del agrado de los teólogos cristianos, deseosos de apropiarse a Platón. El relato contiene también una minuciosa descripción física de ocho esferas concéntricas. Estas esferas están sujetas al cielo por cadenas y mecanismos de acero que estructuran el círculo del universo. La imagen de la figura 2, tomada de la Harmonia macrocosma... de Andreaus Cellarius, reproduce una concepción muy similar de ocho esferas concéntricas que circundan la tierra. Los engranes de la esfera zodiacal, que es la última, recuerdan también el tópico del universo como reloj y Dios como relojero. Una vez más, la evocación del orden y el control para apaciguar e inspirar a las almas inquietas y desordenadas de los hombres.

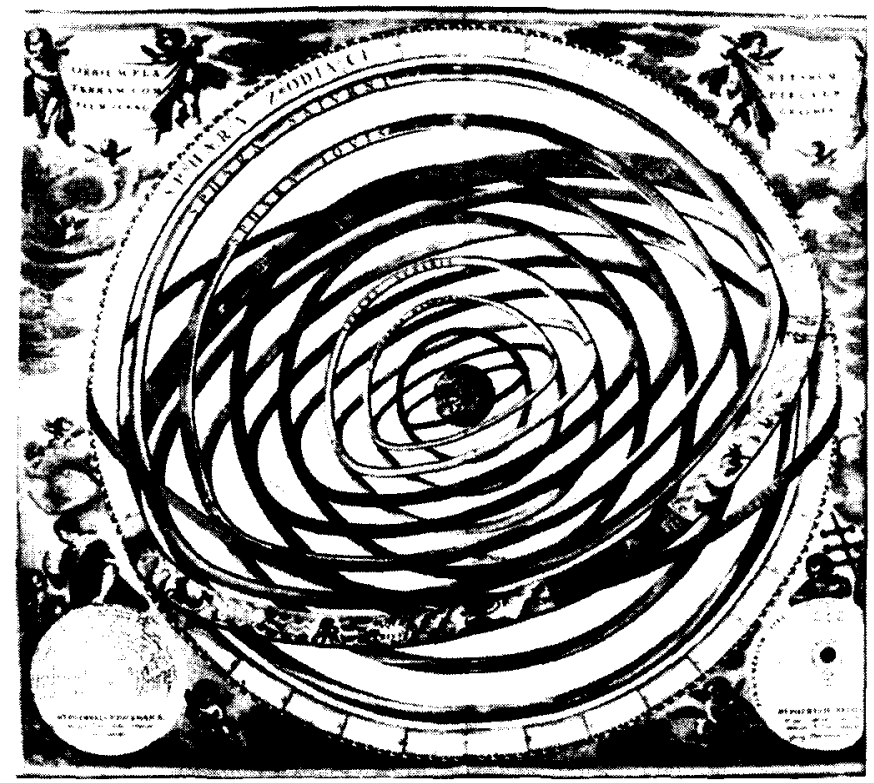

Fig. 2: Andreaus Cellarius, Harmor ia macrocosma seu atlas universalis et novum totius universi creati cosmographiam generalem et novam exhibens (Ámsterdam, 1660). 
En cada una de las esferas platónicas hay una sirena cantando en un tono distinto cada una; las ocho juntas producen una armonía. Pero existe un factor más: en un cerco exterior, a intervalos iguales, están las tres Parcas, que tejen el destino. Ellas acompañan con sus voces la armonía de las sirenas: Laquesis canta sobre el pasado, Cloto sobre el presente, y Atropos sobre el futuro. Mientras cantan, ayudan a impulsar los distintos círculos con las manos. Se trenzan entonces sonido, tiempo y movimiento.

Detrás de estas tres versiones subyace la figura importantísima de Pitágoras, clave incontestable de gran parte de la teoría artística renacentista. Cuenta la leyenda que Pitágoras descubre accidentalmente las leyes de la armonía al oír martillos de distintos tamaños golpeando sus yunques. Observó que a veces el sonido era agradable y a veces discordante dependiendo del tamaño y peso de los martillos. En la figura 3 aparece Jubal, el padre bíblico de la música (Gen. 4:20-22), en la escena de los martillos, y Pitágoras mismo experimentando

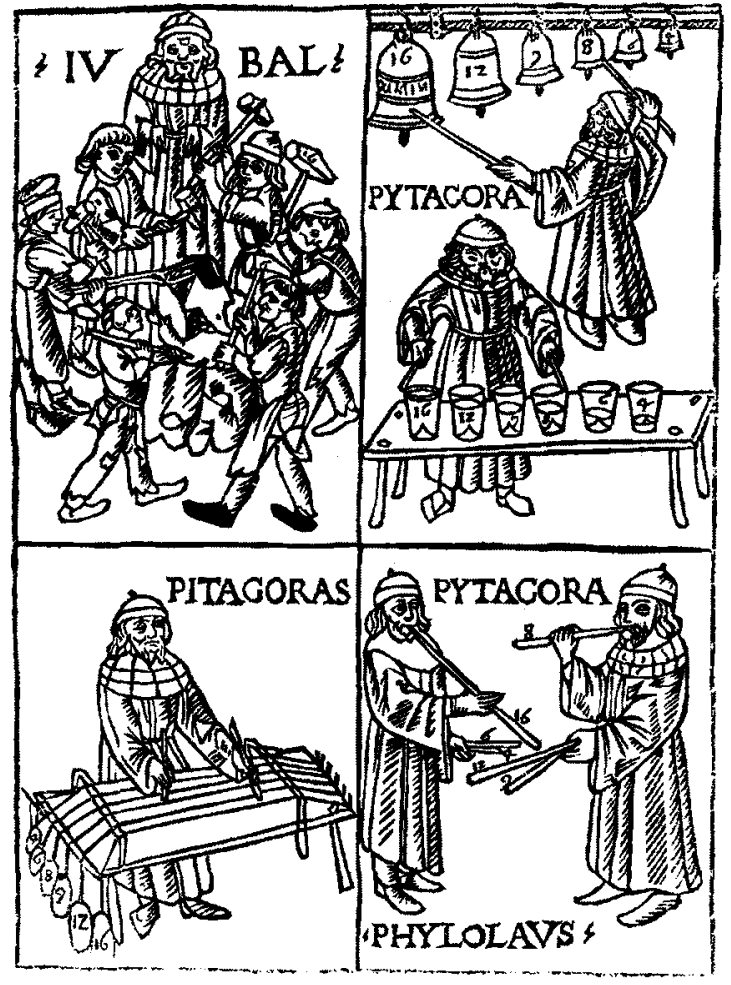

Fig. 3: Franchino Gaffurio, Theoria musicae (Milán, 1492). 
con campanas, vasos de agua, cuerdas tensadas y flautas, corroborando cada vez las mismas proporciones armónicas. La figura 4 contiene en la parte superior un diagrama que resume las armonías pitagóricas a intervalos de 4, 5 y 8 . El hecho de que aparezca un compás al centro del pentagrama nos recuerda la relación estrecha entre la música y la geometría: las materias del Quadrivium eran aritmética, música, geometría y astronomía.

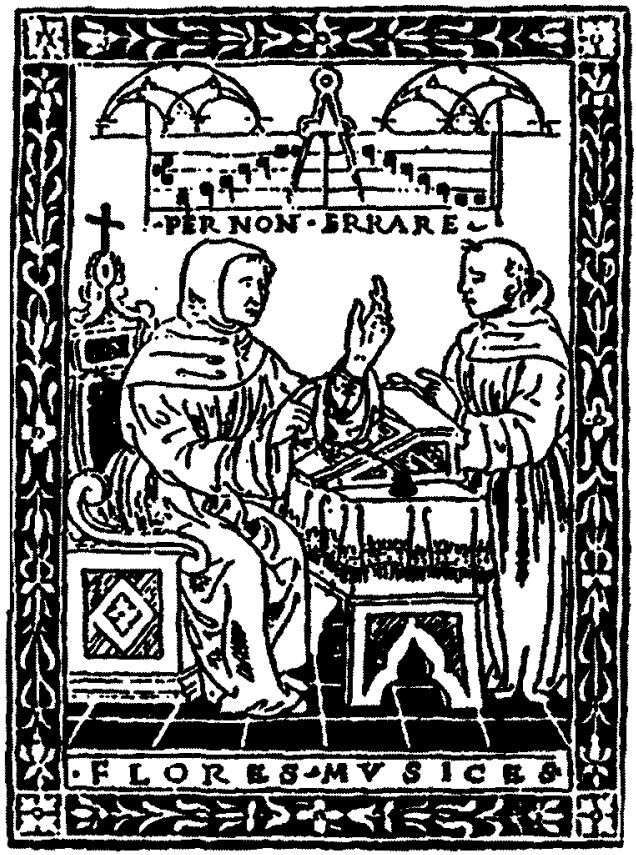

Fig. 4: Pedro de Cannuzi, Regule florum musices collecte ex visceribus multorum Doctorum (Florencia, 1510).

Las proporciones armónicas eran tan constantes, que los pitagóricos pensaron que se podían aplicar también a la distancia entre los planetas. Proponen que están separados por intervalos armónicos numéricamente representables. Describen un sistema de diez esferas (para los pitagóricos el diez era el número de la perfección), cada una de las cuales produce un sonido distinto, y como están a intervalos perfectos, resultan en una música armoniosa. De hecho, llegan a concebir todos los cielos como una escala musical con equivalencias numéricas.

Ahora bien, ya desde la Edad Media había estado en boga la analogía entre el microcosmos humano y el macrocosmos universal. Se creía que las 
proporciones musicales se reflejaban en la naturaleza humana, y filósofos pitagóricos tales como Boecio en el siglo vi describieron la llamada musica humana, la música incesante pero silenciosa producida por cada ser humano, especialmente por la resonancia entre el cuerpo y el alma. Esta musica humana era el reflejo especular de la musica mundana, que en este contexto equivaldría a la de las esferas. Esta idea se vio reforzada por el fenómeno de vibración simpática: cuando una cuerda de cualquier instrumento se pulsa, otras cuerdas afinadas a la misma nota vibrarán al mismo tiempo, aunque de manera casi silenciosa. Analógicamente, en este universo vibrante, las vibraciones de la naturaleza humana y la armonía de las esferas se reflejan entre sí, y los intervalos "perfectos" de 4 y 5 emulan los coros celestiales (Franklin 2001: passim).

La figura 5 es el frontispicio de la obra titulada Del Sonare sopra'l basso con tutti li stromenti de Agostino Agazzari (1607) sobre la teoría musical del bajo continuo. En la esquina inferior izquierda aparece un esquema de las esferas celestes con el lema Ex motu armonia, del movimiento, la armonía. El uso del bajo continuo, que floreció en el Renacimiento, hace por demás evidente la naturaleza contrastada de los conceptos detrás del arte.

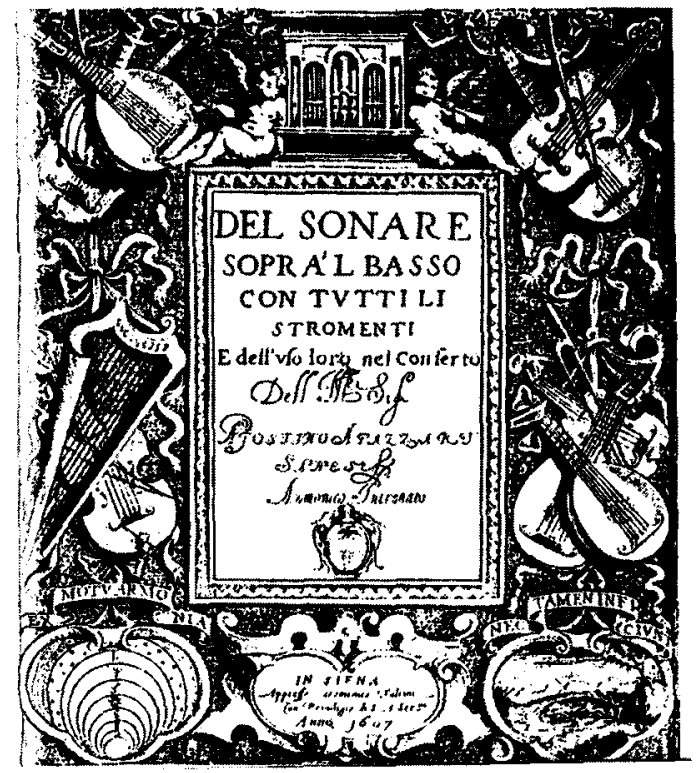

Fig. 5: Agostino Agazzari, Del sonare sopra'l basso con tutti li stromenti... (Siena, 1607). 
La presencia del bajo continuo hace que las notas altas adquieran un nuevo brillo: la noción misma del acompañamiento musical nace en relación con el contraste armónico, análogo al del universo (Della Corte y Pannain 1950: 526, 528). Otro ejemplo representativo se halla en De harmonia musicorum de Franchino Gaffurio (1518) (figura 6), que contiene un grabado de Gaffurio dando cátedra sobre las proporciones armónicas. Un estandarte nos revela sus palabras: Harmonia est discordia concors. Retomamos aquí el tópico de la discordia concors identificado ya plenamente con la armonía. En ese sentido, armonizar es reconciliar, y el término debe entenderse aquí en todas sus acepciones; es decir, no sólo en sentido práctico, musical, sino también en sentido abstracto, en particular en el campo de la teología. La noción se aplica por ejemplo a los afanes de los florentinos neoplatónicos (que mencionaré a continuación) por reconciliar a Platón y Aristóteles, o a la Antigüedad pagana con el cristianismo. Armonizar, luego entonces, es ligar o, mejor dicho, adquiere el significado profundo de re-ligar en el sentido de religión.

Para cristianizar esta versión pitagórico-platónica de la cosmografía, a lo largo del medievo se le fueron añadiendo al relato detalles y modificacio-

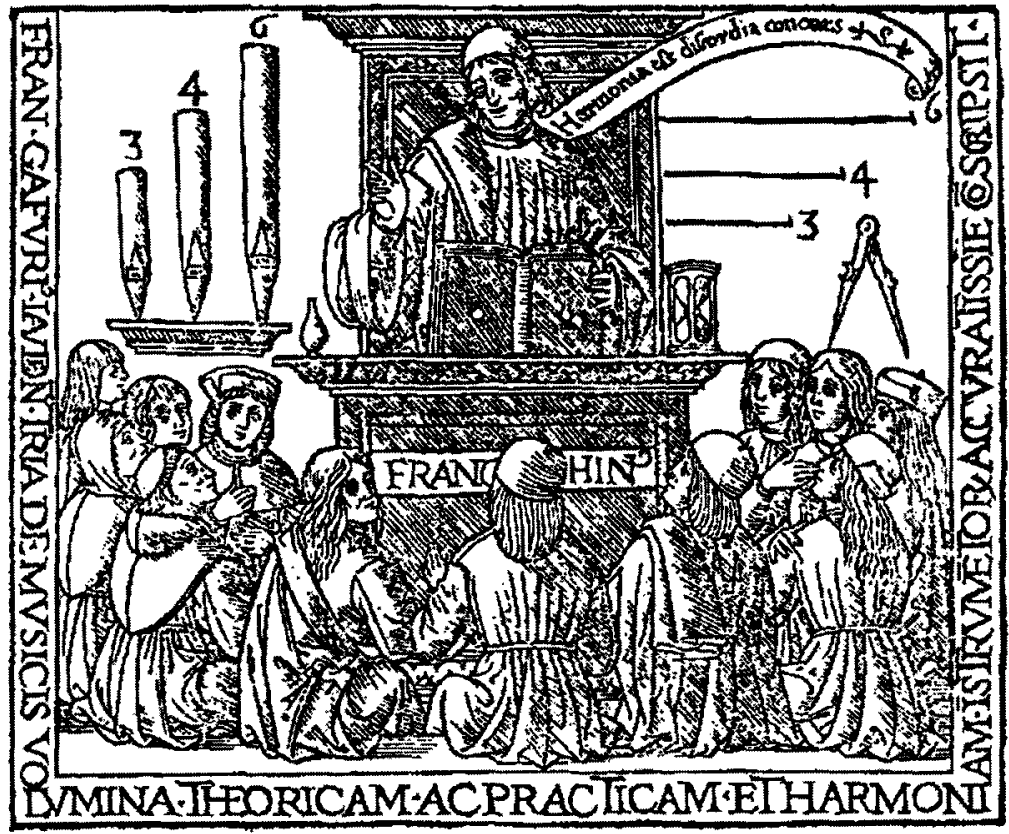

Fig. 6: Franchino Gaffurio, De harmonia musicorum (Milán, 1518). 
nes. En lugar de sirenas, eran ángeles los que impulsaban las esferas para hacerlas girar, como ya se vio en el poema de Randolph. En ocasiones se llegó incluso a establecer la correspondencia analógica entre las esferas celestes y las nueve jerarquías angélicas descritas por san Dionisio el Areopagita. Asociar ángeles y música es algo muy antiguo; data por lo menos de tiempos bíblicos. El ejemplo arquetípico de la función musical de los ángeles en la tradición judeo-cristiana es el de las multitudes de ángeles que cantan eternamente el "santo, santo, santo" en la esfera más alta, la más próxima a Dios. La topografía de la Divina comedia refleja esta disposición simétrica de círculos concéntricos que culminan en el círculo más alto, que se le revela a Dante en forma de una gran rosa blanca formada por un enjambre de ángeles que entonan sin cesar las alabanzas del nombre divino, y que, libando como abejas, hacen de su amor por la divinidad el motor de todas las esferas (Paraíso 28, 29).

El factor Amor como motor del universo fue el que más difundieron los llamados neoplatónicos florentinos encabezados por Marsilio Ficino y Pico della Mirandola. Le añaden a su vez ingredientes tomados de distintas tradiciones místicas y esotéricas como el hermetismo y la cábala judía. Por ejemplo, uno de los aforismos herméticos más difundidos en esta época dice simplemente "Lo de arriba, abajo, y lo de abajo, arriba". Se asocia, entre otras cosas, con imágenes poéticas de escaleras, escalones y, claro, escalas. Hay incontables ejemplos de poesía con tema musical en donde la música humana asciende gradualmente hasta llegar a la esfera más alta para ahí recibir primero la música celestial y luego fundirse con ella.

Con el afán de describir un universo "perfecto" o al menos "perfectamente representable", la creación entera se acomodaba al sistema escalonado y jerárquico. En el peldaño más bajo, las piedras y los minerales; después el reino vegetal seguido del animal para culminar con el hombre. Pero el pensamiento analógico no para ahí. En su Oración sobre la dignidad del hombre, Pico della Mirandola explica por qué el ser humano ocupa un lugar tan privilegiado en la escala de la creación: los hombres tienen la facultad única de elegir en qué nivel ubicarse. Así, los que viven sin sentir serán como piedras; los que viven sin mover sus afectos serán como plantas; los que viven sólo de manera sensual serán como las bestias, y los que usan su razón para los más altos fines serán como los ángeles. Lógicamente, concluye Pico, el hombre que sabe usar la inteligencia tenderá siempre hacia el bien más alto. Así, entre más desarrollado esté, con más ahínco buscará ubicarse en la dimensión angélica. El solo hecho de vislumbrar esta posibilidad le produce una exaltación parecida a la de los ángeles cantores. Es interesante observar que el objeto de las alabanzas se ve aparentemente des- 
plazado de Dios al hombre. Aunque se ha convertido en un lugar común decir que el humanismo conduce al homocentrismo, esto no es así en principio, y en el caso de Pico se demuestra fácilmente: la única grandeza del hombre es poder acercarse a Dios libremente. Dejar de hacerlo equivale a renunciar a esta grandeza (Pico 1972: 231-237).

Hay incontables ejemplos de poemas que describen un ascenso desde el punto más bajo hasta el punto más alto, o viceversa, recorriendo toda la escala o diapasón de la creación. Tal es el caso de un himno de Milton de 1645 en el que los ángeles bajan del cielo tocando instrumentos y cantando para celebrar el nacimiento de Cristo (Grierson y Bullough 1951: 460-461). (El tema de la Natividad, por supuesto, es uno de los que más explotan la idea de los ángeles músicos, tanto en poesía como en las artes visuales.) En este himno los pastores son los testigos privilegiados del portento. Miles de querubines y serafines bajan cantando con sus arpas, y producen una música que sólo se había oído una vez antes: en el Génesis, cuando Dios, según Milton, "colgó al mundo de sus bisagras" y puso a las constelaciones en su lugar:

At last surrounds their sight

A Globe of circular light,

That with long beams the shame-fac'd night array'd,

The helmed Cherubim

And sworded Seraphim,

Are seen in glittering ranks with wings displaid,

Harping in loud and solemn quire,

With unexpressive notes to Heav'ns new-born Heir.

Such Musick (as 'tis said)

Before was never made,

But when of old the sons of morning sung,

While the Creator Great

His constellations set,

And the well-ballanc't world on hinges hung,

And cast the dark foundations deep,

And bid the weltring waves their oozy channel keep.

Ring out ye Crystal sphears,

Once bless our human ears,

(If ye have power to touch our senses so)

And let your silver chime

Move in melodious time;

And let the Base of Heav'ns deep Organ blow.

And with your ninefold harmony 
Make up full consort to th'Angelike symphony.

("Hymn", vv. 81-103)

Para Milton, el coro de ángeles es la música de las esferas, que para él son nueve, una por cada jerarquía, y juntas crean una armonía de nueve tonos. Así como el arco iris fue la señal de la alianza después del diluvio, para Milton y muchos más, la música es el nuevo arco que une cielo y tierra, la nueva cuerda que re-liga al hombre con Dios. La conmemoración de la Navidad a través de la música sacra promete que el tiempo correrá hacia atrás y la humanidad regresará a la edad de oro en la que no existía ni la vanidad ni el infierno.

\section{For if such holy Song}

Enwrap our fancy long,

Time will run back, and fetch the age of gold, And speck'ld vanity

Will sicken soon and die,

And leprous sin will melt from earthly mould, And Hell it self will pass away,

And leave her dolorous mansions to the peering day. $[\ldots]$

$$
\text { ("Hymn", vv. 104-111) }
$$

Debido a una motivación que he dado en llamar "interés diapasónico" por ser un afán de recorrer el diapasón entero (recordemos que diapasón viene de $\delta \iota \alpha$, a través, y $\pi \alpha \sigma \omega v$, de todas las cuerdas o notas), el infierno tiende a ser muy popular también en estos poemas. En 1696 John Dryden escribió una oda en honor de Henry Purcell con ocasión de su fallecimiento, oda que fue musicalizada por John Blow, íntimo amigo de Purcell (Dryden 1933: 117). En ella Dryden compara a Purcell con Orfeo que baja a los infiernos para rescatar a Eurídice. Sin embargo, Dryden afirma, no sin sentido del humor, que Purcell no podrá entrar al infierno porque el mismísimo diablo le va a impedir el paso. ¿Por qué? Porque Purcell es la encarnación de la armonía, y como el infierno es el reino de la discordia, si lo dejaran pasar el infierno dejaría de existir.

We beg not Hell our Orpheus to restore;

Had he been there,

Their sovereign's fear

Had sent him back before.

The pow'r of harmony too well they knew; 
He long e'er this had tun'd their jarring sphere, And left no Hell below.

("An Ode on the Death of Mr. Purcell", vv. 15-21)

Afortunadamente para el diablo nada de esto es necesario. Como el coro celestial oyó la música de Purcell desde las alturas, los ángeles dejaron caer una escalera -o escala— para que por ahí pudiera subir al cielo.

The heavn'ly choir, who heard his notes from high,

Let down the scale of music from the sky:

They handed him along,

And all the way he taught, and all the way they sung.

Ye brethren of the lyre and tuneful voice,

Lament this lot: but at your own rejoice.

Now live secure, and linger out your days,

The Gods are pleas'd alone with Purcell's lays,

Nor know to mend their choice.

(“An Ode...”, vv. 22-30)

En la célebre "Oda a Salinas" de fray Luis de León, publicada por Quevedo en 1631, volvemos a encontrar la idea del viaje que hace el alma de la tierra al cielo con ayuda de la música, pero en esta ocasión no hay necesidad de bajar al inframundo. Aparecen además otros tópicos neoplatónicos como la memoria recobrada, el recorrido a través de las esferas y las armonías numéricas. La música que toca el organista ciego, Francisco Salinas, hace que el alma deje de estar sumida en el olvido y recuerde su origen divino para ascender hasta "la más alta esfera" (fray Luis 1970: 178-179)

El aire se serena

y viste de hermosura y luz no usada,

Salinas cuando suena

la música estremada

por vuestra sabia mano gobernada.

A cuyo son divino

el alma, que en olvido está sumida, torna a cobrar el tino

y memoria perdida

de su origen primera esclarecida.

[...]

Traspasa el aire todo

hasta llegar a la más alta esfera 
y oye allí otro modo

de no perecedera

música, que es la fuente y la primera.

Y como está compuesta

de números concordes, luego envía

consonante respuesta,

y entrambas a porfía

se mezcla una dulcísima armonía.

("Oda a Salinas", vv. 1-10, 16-20)

De los cuatro elementos aristotélicos, el elemento de la música es el aire por donde viaja, se propaga y se hace audible; de ahí su relación con el vuelo, los astros y los ángeles alados. Lo interesante aquí es que una vez que el alma está instalada en su ámbito verdadero, el éxtasis que experimenta evoca imágenes de agua. Curiosamente, el sentido del oído conduce a una culminación espiritual evocada por una imagen de gran sensualidad táctil.

Aquí la alma navega

por un mar de dulzura, y finalmente,

en él ansí se anega,

que ningún accidente

estraño y peregrino oye y siente.

("Oda...", vv. 30-34)

De aquí en adelante, la emoción va en ascenso y la voz poética se deshace en exclamaciones de exaltación y arrobamiento, para terminar con un melancólico suspiro, pues añora tener en todo momento el impulso etéreo de la música.

En la "Oda a Felipe Ruiz", también conocida como la "Oda cósmica", la misma añoranza se transfiere al momento de la muerte que promete desatar al alma de la prisión del cuerpo, otro tópico neoplatónico. Ofrece un interesante paralelismo con el poema de Randolph arriba citado, además de incluir un vuelo astral. Fray Luis fantasea sobre lo que verá cuando su alma liberada se eleve hasta lo más alto. El poema traza también una línea ascendente, pero es un recorrido menos vertiginoso que en la "Oda a Salinas". Con un ritmo más pausado, se detiene a contemplar cada elemento, desde la tierra, "pesadísima", pasando por el agua y el aire, hasta las centellas de los astros.

¿Cuándo será que pueda,

libre, de esta prisión, volar al cielo,

Felipe, y en la rueda 
que huye más del suelo, contemplar la verdad pura sin duelo?

(“Oda a Felipe Ruiz", vv. 1-5)

La "rueda que huye más del suelo" es exactamente el mismo lugar de destino que en la "Oda a Salinas" se designa como "la más alta esfera". Pero la imagen de la rueda tiene de algún modo mayor materialidad; es un referente más mundano, más acorde con las imágenes subsiguientes que aluden al tópico de Dios como arquitecto del universo, plantando cimientos y midiendo con plomadas, separando la tierra del agua.

\section{Entonces veré cómo}

la soberana mano echó el cimiento

tan a nivel y plomo,

do estable y firme asiento

posee el pesadísimo elemento.

Veré las inmortales

colunas do la tierra está fundada,

las lindes y señales

con que a la mar hinchada

la Providencia tiene aprisionada;

Por qué tiembla la tierra, por qué las hondas mares se embravecen; dó sale a mover guerra

el Cierzo, y por qué crecen las aguas del Océano y descrecen...

Y de allí levantado

veré los movimientos celestiales, ansí el arrebatado como los naturales, las causas de los hados, las señales.

Quién rige las estrellas veré y quién las enciende con hermosas y eficaces centellas; por qué están las dos Osas, de bañarse en el mar siempre medrosas. Veré este fuego eterno,

Fuente de vida y luz, dó se mantiene;

Y por qué en el hivierno tan presuroso viene, quién en las noches largas le detiene.

Veré sin movimiento en la más alta esfera las moradas 
del gozo y del contento,

de oro y luz labradas,

de espíritus dichosos habitadas.

(“Oda a Felipe Ruiz", vv. 11-25; 51-70)

A continuación me referiré a un fragmento de la "Epístola a Arias Montano" de Francisco de Aldana, el Divino, de 1577. Habiendo decidido retirarse del mundo, explica que su comunicación con Dios será a través del sonido y la resonancia. El alma hallará su sitio verdadero afinándose "al dulce son de Dios", y esto lo hará reproduciéndolo como un eco.

Pienso torcer de la común carrera que sigue el vulgo y caminar derecho jornada de mi patria verdadera:

entrarme en el secreto de mi pecho y platicar en él mi interior hombre, dó va, dó está, si vive, o qué se ha hecho.

Y porque vano error más no me asombre, en algún alto y solitario nido pienso enterrar mi ser, mi vida y nombre.

Y, como si no hubiera acá nacido, estarme allá, cual Eco, replicando al dulce son de Dios, del alma oído.

Y ¿qué debiera ser, bien contemplando, el alma, sino un eco resonante, a la eterna beldad que está llamando,

$Y$, desde el cavernoso y vacilante cuerpo, volver mis réplicas de amores al sobrecelestial Narciso amante...?

("Epístola a Arias Montano", vv. 43-60)

Es importante observar que en Aldana la experiencia del retorno a "la patria verdadera" es más claramente que en ninguno de los otros ejemplos el fruto de la introspección. En lugar de proponer la música terrena como vehículo de ascenso, Aldana propone la misma música celestial como modelo a imitar con tanta fidelidad como la ninfa Eco, aprovechando espléndidamente la resonante cavernosidad del cuerpo. El gesto del Narciso que se inclina para mirar su imagen se re-elabora aquí de manera singular pues Eco se convierte en imagen y semejanza de Narciso, misma imagen, misma resonancia.

Los tópicos neoplatónicos abundan en este poema; veremos sólo algunas estrofas más que tratan acerca del vuelo psíquico a las alturas. 
Es bien verdad que a tan sublime cumbre suele impedir el venturoso vuelo del cuerpo la terrena pesadumbre.

Pero, con todo, llega al bajo suelo la escala de Jacob, por do podemos al alcázar subir del alto cielo;

que, yendo allá, no dudo que encontremos favor de más de un ángel diligente con quien alegre tránsito llevemos.

Puede del sol pequeña fuerza ardiente desde la tierra alzar graves vapores a la región del aire allá eminente.

¿Y tantos celestiales protectores para subir a Dios alma sencilla, vernán a ejercitar fuerzas menores?

("Epístola...", vv. 106-120)

La pesadez del cuerpo terreno, una vez reconocida, es vencida y superada por la gracia divina en forma de la escala de Jacob, por la que el alma puede "escalar" para llegar "al alcázar... del alto cielo". Una vez ahí, un ángel seguramente hará las diligencias para llevarla al centro de centros. La figura angélica nuevamente está relacionada con el diálogo armonioso entre el alma y Dios, que sube y baja entre el cielo y la tierra.

Ahora comentaré muy brevemente otro poema de John Dryden. Es la "Canción para el Día de Santa Cecilia". En 1683 se formó en Londres una sociedad musical para representar anualmente una composición en honor de santa Cecilia, patrona de los músicos, cada 22 de noviembre. Dryden escribió los poemas para los festivales de 1687 y 1697 . Este poema, que es el de 1687 , fue musicalizado por varios compositores; la versión más conocida es la de Händel, de 1731. El tema central es la armonía. Dryden cuenta la historia del Génesis, a partir de la armonía celeste que puso orden a la discordancia atómica del caos original. La voz "entonada" de Dios ordena a los elementos que tomen su lugar en la danza cósmica, y así una a una, las partes de la creación ocupan sus peldaños en la escala, para cerrar el diapasón con el hombre, cumbre y gloria de todo lo creado.

From harmony, from heav'nly harmony

This universal frame began;

When Nature underneath a heap

Of jarring atoms lay,

And could not heave her head, 
The tuneful voice was heard from high:

'Arise, ye more than dead.'

Then cold, and hot, and moist, and dry

In order to their stations leap,

And Music's power obey.

From harmony, from heav'nly harmony

This universal frame began:

From harmony to harmony

Thro' all the compass of the notes it ran,

The diapason closing full in Man.

("A Song for St. Cecilia's Day", vv. 1-15)

Alude también a Jubal, a quien se atribuye la invención de la flauta y la cítara. En la sección de Jubal se anuncia cómo la música es capaz de controlar las pasiones, para despertarlas o aplacarlas. Las estrofas siguientes son la demostración práctica de esto. En un alarde de virtuosismo técnico, Dryden hace resaltar la musicalidad inherente del lenguaje por sí solo. Desfilan uno a uno los distintos instrumentos para recorrer con onomatopeyas un repertorio equivalente de las distintas emociones. Trompetas y tambores hacen música marcial. Flautas y violines, música amorosa. Por encima de todos reina el órgano, dedicado a la música sagrada. Para Dryden, es el único instrumento capaz de subir al cielo, e incluso "enmendar" los coros celestes. Por eso santa Cecilia, a quien Dryden atribuye la invención del órgano, es superior a Orfeo.

Orpheus could lead the savage race,

And trees unrooted left their place,

Sequacious of the lyre;

But bright Cecilia rais'd the wonder high'r:

When to her organ vocal breath was giv'n,

An angel heard, and straight appear'd,

Mistaking earth for heav'n.

("A Song...", vv. 48-54)

Si bien Orfeo era capaz de amansar a las fieras y hacer moverse a los árboles, santa Cecilia fue capaz, según Dryden, de hacer aparecer a un ángel que al oír su música se confundió, y pensó que la tierra era el cielo. Esta imagen humorística aunque de gusto un tanto dudoso forma parte de la misma tradición estética que el Aristóteles cantante de Thomas Randolph.

En el gran coro final, dice que las esferas celestes son impulsadas por la música sacra que emiten en alabanza del Creador. Y cuando llegue el día del Juicio Final, será una trompeta la que anuncie el fin de la procesión cósmica. 
As from the pow'r of sacred lays

The spheres began to move, And sung the great Creator's praise

To all the blessed above;

So, when the last and dreadful hour

This crumbling pageant shall devour,

The trumpet shall be heard on high,

The dead shall live, the living die,

And Music shall untune the sky.

$$
\text { ('A Song...', vv. 55-63) }
$$

A manera de colofón, quiero proponer una cuestión de lectura artística. En este trabajo he aludido a algunas formas evidentes que tuvo el Renacimiento de plasmar las ideas en torno a la música de las esferas en las áreas de la música y la poesía. Música y poesía comparten un elemento de notación gráfica que la estética renacentista no podía pasar por alto, pues ambas se transmiten a través de manuscritos y libros. El soneto, por ejemplo, tiene una forma gráfica reconocible a simple vista. Y los documentos musicales de canciones a menudo incluyen letras iniciales o capitulares iluminadas con gran opulencia.

Me he referido a escalas cósmicas, círculos concéntricos y danzas atómicas. Este movimiento armonioso, basado en una estética de la simetría y la proporción, se encuentra también en un arte gráfico que suele no tomarse con demasiada seriedad. Me refiero al arte caligráfico. Hay modalidades de caligrafía ornamental renacentista que reflejan esta visión musical del mundo y el cosmos, con trazos que son ires y venires, ascensos y descensos perfectamente ordenados, y que, sin pretender ser la representación gráfica de nada, son una verdadera danza de la pluma en el papel. Obsérvese por ejemplo el aspecto general de la figura 7 . Más aún, el lenguaje que se usa para describir esta caligrafía es evidentemente musical, pues se habla por ejemplo de florilegios y arabescos. Hay además espirales de formas diversas que sugieren vibraciones y pulsaciones, que también se pueden describir poéticamente, como quien describiera una rúbrica anticuada llena de garambainas y volutas, puntos, tildes y espirales, diamantes y toda suerte de extravagantes garabatos.

Está también presente un factor de decoro gráfico que tiene que ver con la naturaleza de la página como unidad artística, que exige no dejar espacios vacíos que entorpezcan o "ensucien" el aspecto general de la página. Mucho antes de que se describiera la estética barroca como el miedo al vacío, hay entre los preceptores del arte caligráfico la consigna de no dejar ningún espacio hueco. Cito al calígrafo francés Jean de Beauchesne, representa- 
do en la figura 8: "Así como en la naturaleza no existe el vacío, tampoco lo hay en las cosas espirituales. Todo recipiente está lleno, si no de líquido, al menos de aire..." (Beauchesne 1988: 53).

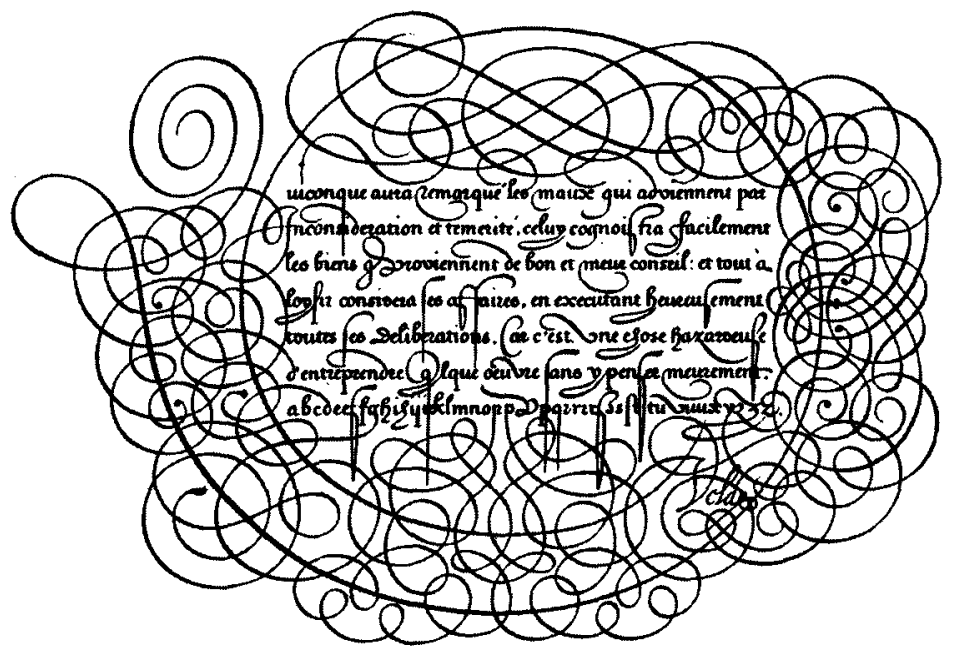

Fig. 7: Van den Velde, Thresor Literaire (Rótterdam, 1605).

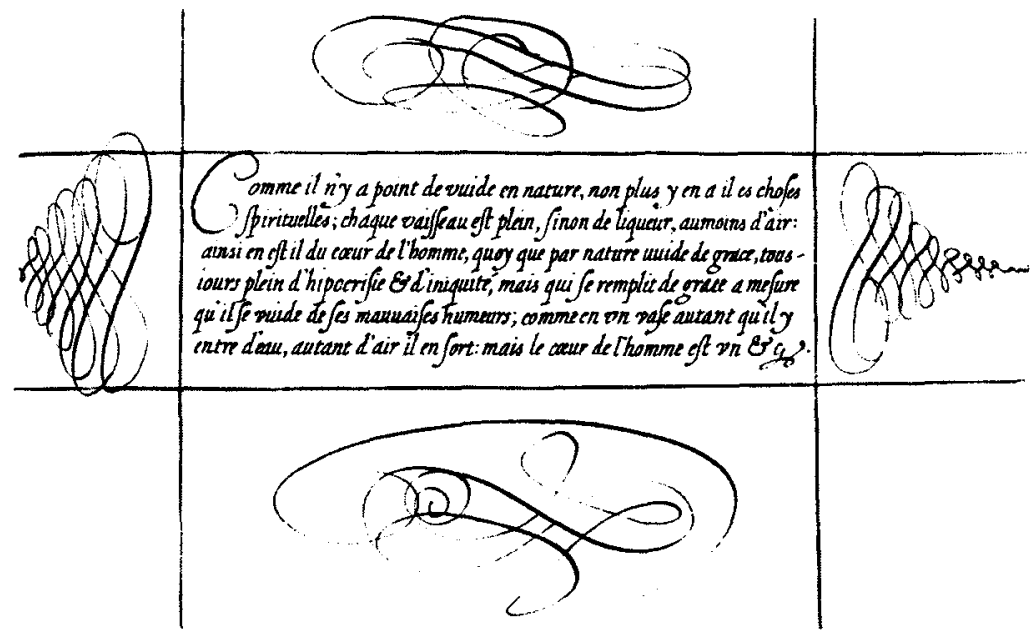

Fig. 8: Jean de Beauchesne, regalo para la princesa Isabel I, ca. 1610 (sin título). 
Mi propuesta ahora es leer en esa consigna no un adorno superficial, sino un intento más de trazar los caminos del aire y de crear puentes, una estética del movimiento y la sonoridad interpretada gráficamente por la misma mano humana que tañe laúdes y escribe poemas, como en la figura 9. ¿El artista dibuja y escribe oyendo música? ¿Compone música dibujando? Tenemos ejemplos de poesía renacentista gráfica, poemas que dibujan con versos largos y cortos figuras de diamantes o relojes de arena, de cruces y de liras. De igual modo, las notas en los pentagramas dibujan figuras, crestas y valles, escaleras y puentes. Propongo así sumar el arte caligráfico a estos dos artes "superiores", como otro modo de trazar caminos, como un arte abstracto de laberintos o mandalas hipnóticos que revelan la creencia en un universo gozoso y trascendente, donde la quintaesencia aristotélica se vuelve visible, y donde la vibración es reina.

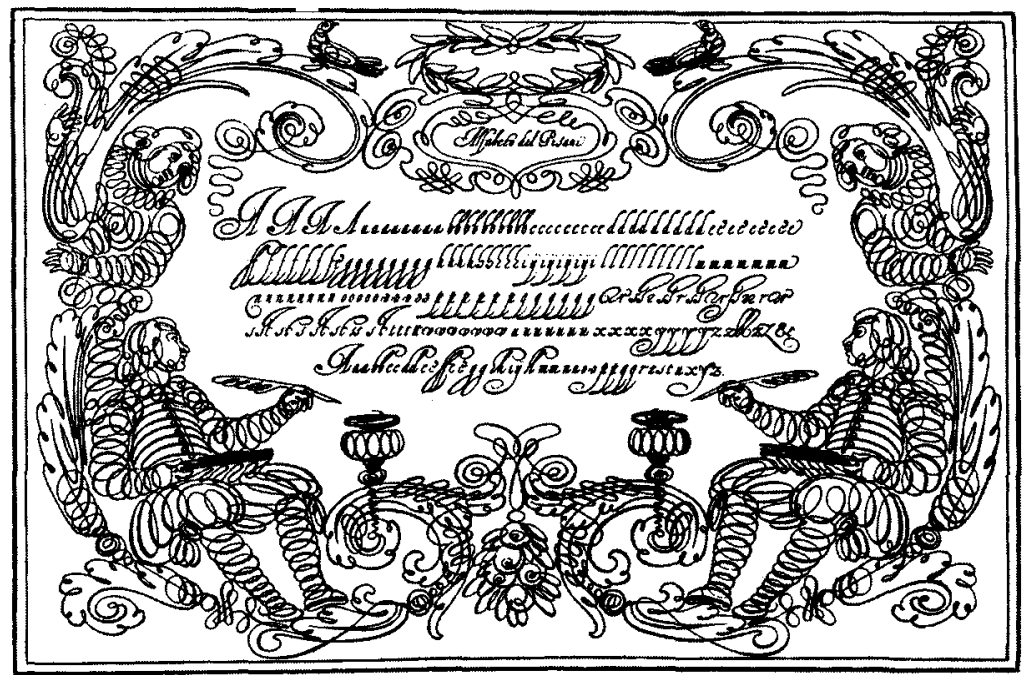

Fig. 9: Pisani, Tratteggiato da penna (Génova, 1640).

Bibliografía

Beauchesne, Jean de. 1988. Sin título, regalo para la princesa Isabel, en Kathryn A. Atkins, Masters of the Italic Letter: Twenty-two Exemplars from the Sixteenth Century. Boston: David R. Godine. [Reproducción del manuscrito en la Newberry Library de Chicago, Wing ZW ZIV 639 B382.] 
Cervantes, Miguel de. 1969. El ingenioso hidalgo Don Quijote de la Mancha. Ed. y pról. de Américo Castro. México: Porrúa. [Segunda parte, caps. xxxix y xl.]

Cicerón. 1866. De la république. Trad. de J. V. LeClerc, avec le texte latin et des notes. París: Hachette.

Cicerón. 1981. Tratado de la república... Trad. de Francisco Navarro y Calvo y Juan Bautista Calvo. México: Porrúa.

Corte, A. della y G. Pannain. 1950. Historia de la música. Tomo primero: De la Edad Media al siglo XVIII. Barcelona: Labor.

Dryden, John. 1933. The Best of Dryden. Louis L. Bredvold, University of Michigan, ed., introd., notes. Nueva York: Ronald Press.

Franklin, Ruth. 2001. "Good Vibrations", reseña de Stuart Isacoff, Temperament..., en The New Republic, Dec. 10, 2001: www.thenewrepublic.com

Isacoff, Stuart. 2001. Temperament: The Idea that Solved Music's Greatest Riddle. Nueva York: Alfred A. Knopf.

Luis de León, fray. 1970. La perfecta casada. Cantar de los cantares. Poesias originales. Introd. y notas de Joaquín Antonio Peñalosa. México: Porrúa. (Col. Sepan cuantos..., 145)

Mirandola, Pico della. 1972. "Oración sobre la dignidad del hombre”. Alejandro Herrera Ibáñez, Antología del Renacimiento a la Ilustración. México: UNAM. (Lecturas universitarias, 15. Textos de historia universal)

Randolph, Thomas. 1951. "Poetry and Philosophy". H. J. C. Grierson y G. Bullough, The Oxford Book of Seventeenth-Century Verse. Oxford: Clarendon.

Tillyard, E. M. W. 1984. La cosmovisión isabelina. Trad. de Juan José Utrilla. México, FCE.

Traherne, Thomas. Commentaries of Heaven. BL Add. MS 63054. 